\title{
Review of the Acceptance Tests of the W7-X Superconducting Magnets
}

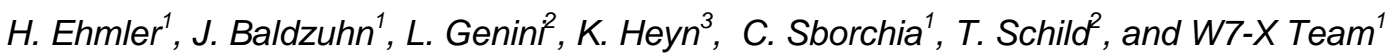

${ }^{1}$ Max-Planck Institut für Plasmaphysik, Euratom Association, D-17491 Greifswald, E-mail: ehmler@ipp.mpg.de

${ }^{2}$ CEA Saclay, FR-91191 Gif-sur-Yvette-Cedex

${ }^{3}$ BNN GmbH, D-97076 Würzburg

The W7-X magnet system consists of 50 non-planar coils of five different types and 20 planar coils of two different types. Factory acceptance tests of the non-planar coils are carried out at the manufacturer site of Babcock-Noell, Germany, and for the planar coils at Tesla Engineering, UK. They consist of electrical insulation checks, mass flow measurements, leak tests and sensor checks. In the test facility of CEA Saclay, France, each coil is cooled down to $\sim 5 \mathrm{~K}$ and operated at nominal current. At least one coil of each type is quenched by increasing the inlet temperature. Results of the mass flow measurements and the quench tests are presented. The manufacturing and testing progress is reviewed and the impact of technical failures is discussed. In conclusion, the scope of the tests allows a very strict quality control. This experience is highly beneficial for the construction and testing of similar components for future superconducting fusion experiments.

Keywords: Superconducting coils, fusion magnets, quality assurance tests

\section{Introduction}

The superconducting coil system of the Wendelstein 7-X stellarator (W7-X) [1] consists of 50 nonplanar and 20 planar coils [2]. All coils have to pass an acceptance test which is divided into two parts. The first part is carried out at the manufacturer at room temperature (factory test) and the second part at cryogenic temperature in a dedicated test facility (cold test). The cold tests are performed at the Commissariat a l'Energie Atomique (CEA) in Saclay, France. The factory test 
basically includes high-voltage (HV) DC and AC tests, leak and flow tests, visual inspections and sensor checks. The objective of the cold tests is to demonstrate the capability of the coil to work properly under cryogenic conditions. Boundary conditions, details of the test procedure and specified values have been given elsewhere [3-5].

This paper is organized as follows. In section 2 a statistical overview about the main tests is presented. The technical failures of the coils which were detected by the tests are briefly summarized. In section 3 important test results, which have emerged by comparing data of different coils, are highlighted. In section 4 the experience with cold testing is discussed in terms of technical items, interface and documentation issues. Finally, the progress of the project is reviewed in section 5 and a conclusion is drawn in section 6 .

\section{Statistical Overview}

Up to now, only a small fraction of the coils have passed all acceptance tests. Several coils have failed during cold test and had to be sent back to the manufacturer for repair (mainly high voltage insulation and leak problems). Therefore, some coils have been in the acceptance process for more than two years and repetitive tests have been carried out. In the following, only the essential parts of the acceptance tests will be more closely examined in terms of throughput and failure at a different test stage. These are the tests at cryogenic temperature and the high voltage DC tests under low gas pressure (Paschen-minimum conditions) [6]. The results of three years are summarized in Table 1. It can be seen that more cold tests have been performed than individual coils were in test. This is caused by retesting coils which had to be repaired because of failures. Table 1 also shows that a large fraction of all tests failed due to technical reasons of the test facility. These failures will be discussed in more detail in section 4 and section 5 . Concerning the coils, the tests under nominal current (safety margin, quench, joint resistance) were generally successful. All mass flow measurements of the superconductor were within specification (see section 3). The most severe technical item to be solved has been the high voltage strength on all coils. High voltage tests under Paschen-minimum conditions have revealed electrical insulation defects, which had not been found under air or high vacuum. These tests are presented in detail in [7]. Paschen tests were carried out at four sites: CEA (France) BNM Zeitz (Germany), 
Ansaldo Superconduttori (Italy) and IPP Greifswald (Germany). The failure rate in these tests was nearly $100 \%$ in the beginning. Over time this rate has decreased by the accumulating manufacturing experience. Failures were mainly due to voids and cavities present in the winding pack after vacuum impregnation and insufficient glass-epoxy hand-wrapped insulation, which could be located after the Paschen tests.

The second but most severe technical item has been the occurrence of helium leaks. On two planar coils, leaks in the aluminum welds of the interlayer joint occurred during cool-down. On one planar coil a cooling pipe of the casing showed a large leak at room temperature. This was caused by stress corrosion of the stainless steel pipes at the soldered connections with copper heat sinks. The soldering procedures for the casing cooling pipes of all coil types had to be revised. In consequence, a lot of coils already fabricated have been reworked after a risk analysis, although having been leak-tight during the tests. AC tests (impulse and impedance tests) were applied to detect short circuits during the fabrication of the winding packs [8]. Short circuits in double layers were detected and could be repaired on three non-planar coils. One winding pack was replaced by the supplier because a short circuited winding. Another winding pack was lost by a superconductor blockage with resin. All other quality issues could be resolved by repair or changes in the components. Apart from failure of single sensors, the coil instrumentation with temperature sensors seemed to be adequate. The strain gauges, however, did not deliver reliable signals. The gluing of the sensors and the self-heating due to the measurement current have been identified as error sources. The displacement transducers showed a high failure rate due to stick-slip effects. An optical measurement is recommended instead.

\section{Selected Test results}

Some results of the cold tests have already been published [3-5]. The present article focuses on flow measurements and on quench tests. Due to the progress of the project, a much larger data basis is available up to now and comparisons between coils can be done on a more substantial basis. 


\section{a) He flow tests at RT}

All non-planar winding packs have been produced. The helium flow of each has been measured at room temperature. Each of the six double layer lengths (DLL) has been measured individually at the manufacturer. The data of Figure 1 refer to an inlet pressure of 20 bar at $293 \mathrm{~K}$. Almost all flow rates lie within a tolerance band of $\pm 20 \%$ around the reference value of $4700 \mathrm{Nl} / \mathrm{h}$. For the planar coils, the production of the winding packs is not yet finished. Some results of the flow measurements at cryogenic temperature are given in [3]

\section{b) Quench tests}

Except for non-planar type 2, at least one coil out of ten from each of the seven different coil types has been subjected to a quench test. All tests passed successfully and showed an even higher safety margin than specified [3]. Therefore it was decided not to quench every coil as originally foreseen. As a beneficial side effect a time saving of 1-2 days is achieved for each coil which is not quenched. The remaining coils undergo a safety discharge at full current instead of the quench. The quench appears always in innermost double layer (highest magnetic field). The behavior during quenching seems to be quite similar for all non-planar coils tested so far. This is illustrated by the quench speed shown in Figure 2. The speed of the normal conducting zone was calculated by the temporal increase of the double layer resistance. This calculation is only valid for the early phase of the quench when the change of copper conductivity due to heating can be neglected. The quench is characterized by a rapid increase of quench velocity from $10 \mathrm{~m} / \mathrm{s}$ to values above $100 \mathrm{~m} / \mathrm{s}$. Pressure and temperature increase after the quench are comparable for all non-planar coils tested. Figure 3 depicts this behavior for the temperature of the innermost double layer. In conclusion, up to now only one type of quench has been observed. This is in contrast to the DEMO coil where also much slower quenches occurred [9]. Also shown in Figure 3 is the temperature increase after a pure safety discharge without a preceding quench, which is much lower. For the planar coils similar results are obtained. 


\section{Experience with testing}

During the three years experience in testing the W7-X coils, a lot of issues concerning the test facilities and procedures had to be resolved. These issues can be categorized into: technical failures, interface problems and documentation. It is the aim of this chapter to describe corrective actions undertaken because of their potential relevance for future projects.

\section{a) Technical failures}

The most time-critical issues are of course technical failures of the test facility itself, since they usually lead to delays in the project schedule. The impact is especially high when the test capacity is fully used or when there is no redundancy to bypass the technical difficulties. The most severe accident in this respect has been a subsequent breakdown of the turbine in the helium refrigerator. This accident was caused by a failure of a non-return valve in the vicinity of the compressor and lead to a wide contamination of the helium circuit with oil. The induced shutdown of the refrigerator amounted for 5 months, including a 4 weeks purging operation with isopropanol alcohol and subsequent drying. All other unexpected events had no significant impact on the schedule since only one cryostat was affected and testing of coils could proceed in parallel with repair work.

A leak in a brazed connection of a helium supply tube appeared during cool-down in the winding circuit of planar coils. This leak was at first attributed to the coils themselves, but could be identified later after warming up to be in the facility. Because of the common hydraulic connection of two coils, a leak could not be allocated to an individual coil. To overcome this constraint, two non-return valves have been added into the outlet circuit of the coils, by which it was possible to pressurize only one coil. A second type of leak appeared in the nitrogen thermal shield of the cryostat. This is composed of a segmented two wall container made of stainless steel in which liquid nitrogen is flowing. The leak made a cooling down impossible because of the heat conduction of the leaking nitrogen gas. Leak searching took several weeks. During this 
intervention several meters of weld seam were repaired and small parts had to be removed from shield.

The high voltage insulation of the test facility did not meet fully the requirements. For some bare metallic parts the insulation is purely based on a sufficient distance. This so-called 'vacuum insulation' turned out to produce current 'spikes' in the range of some hundred $\mu \mathrm{A}$ at test voltages of some $\mathrm{kV}$, which interfered with the tests of the coil insulation itself. The problem could be partly overcome by conditioning discharges. During the Paschen tests after warm-up the coil was disconnected from the high current part of the facility and the high voltage was supplied over a bushing to the quench detection cables. The terminal ends of the coil were insulated with shrinkage tube. This test was very sensitive and showed no parasitic leak currents. The tests under vacuum and room temperature were replaced by the Paschen test. One test at maximum voltage in cryo-vacuum has been maintained, which is regularly performed after the current tests.

A problem for the electrical tests at full current has been a degradation of the gold-plated contacts of the demountable bus bar joints. These were exhibiting a resistance of more than $100 \mathrm{n} \Omega$ and thus producing a too high heat load. In consequence, the foreseen test temperature of $5.7 \mathrm{~K}$ could not been reached on one non-planar coil. All gold plated contacts are now renewed at regular intervals.

For some coils the measurements of the interlayer joint resistance have also shown too high values. The quench detection wires serve as voltage taps for this purpose. Too high values only occurred at double layers which have voltage taps with one end connected to the coil terminal. It is anticipated that the effect is related to the terminal ends of the coil. The contact resistance to the normal conducting, demountable, connection to the bus bar probably causes an artificial voltage drop by current re-distribution along the cable. This hypothesis will be examined by measurement with voltage taps attached more far away from this connection, where the current is already fully distributed into the superconductor. 
One test cycle had to be aborted because of a filter blockage in the helium circuit of the coil windings due to metallic chips. The origin of this material (from the coil or the test facility) is not fully clear. As corrective action the filter was cut and replaced by a new one and additional demountable filters were introduced. Other failures e.g. in diffusion pumps occurred, but these events are either not regarded specific to the cold test facility or were of minor importance.

\section{b) Interface issues}

In a multinational collaboration, interface issues are extremely important. A common basis of technical documentation, such as specifications, drawings, labeling etc. in an early phase is required. The main interface issue encountered during cold testing was the location of the coil terminals in space, which exceeded the allowable tolerances of the test facility bus bar connections. These are made for each coil type by a set of intermediate superconductor lengths which is not flexible. It turned out that coils of the same type showed large geometrical deviations of the connecting flange position and could not be connected by the same set of bus bars. Corrective actions from all sides were undertaken, i.e. geometrical surveys of the as-built components, modifications of bus bars, repetitive bending of coil terminals and re-welding of flanges. Although this problem could be regarded as specific to the W7-X coils, it demonstrates however the importance of a clear interface definition including the allowable tolerances. Some minor problems were related to labeling of hydraulic connections and quench detection cables or deviating checklists for incoming and outgoing inspections.

\section{c) Documentation}

The documentation of the acceptance tests for the W7-X coils turned to be out a non-trivial task, especially because a lot of non-conformities were encountered. These had to be followed during release of corrective actions, i.e. eventually repair at the manufacturer and retesting the coil or modifications during further assembly. Updating documents by proper versioning has been essential. The documentation of the cold tests consists basically of three levels. The top-level document is a tabular overview about the main achieved parameters with hyperlinks to detailed 
reports (second level). Each test is documented by a test report containing further information as signal plots and tables. In case of a non-conform result the test is marked as 'not valid' and a non-conformity report is created. On the third level are the time traces of all sensors during cold test as a zipped archive of ASCII files with coarse time resolution for cool-down and warm-up and fine time resolution for quench and fast discharge. All data were transmitted via ftp server, followed by signed hard-copies.

A general recommendation is to standardize documents as much as possible, while maintaining enough flexibility to account for technical failures and other unforeseen events. A binding list of relevant English technical expressions should be established between all partners from the beginning to avoid misunderstandings and to make searching for keywords more easy.

\section{Project progress and time-planning}

In the beginning of the project, a production rate of two non-planar and one planar coil per month and a testing rate of 20 coils per year was envisaged. It was assumed that the rate of coil acceptance would be only slightly lower to the rate of testing. All assumptions have not been met

in reality. The delays have been due to the quality issues and design changes [10] within the coils themselves on the one hand and technical failures in the test facility on the other hand. In 2005, the test facility had been idle for $1 / 2$ year due to a lack of coils, whereas in 2006 cold tests could not be performed for five months due to the turbine failure. The delays in production and the failures of the test facility do not have the same impact on the total project schedule. The latter is based on the availability of accepted coils for further assembly. Since not all types are needed at the same time, the order of testing has been optimized with respect to the demands of assembly. From the present experience it can be concluded that the initial projection of 20 coils per year can be reached, provided that the testing proceeds without major failures and the full test capacity is used. Figure 4 shows the present status (July 2006) and the time planning for 2006, where the production rate will exceed by far the rate of testing. In consequence, the coil testing will be one bottleneck for the total project schedule within the next years. 


\section{Conclusions}

The tests of the superconducting operation of the W7-X magnets have been generally successful. The introduction of the Paschen test has drastically improved the insulation quality. The detection of leaks during acceptance tests led to revisions in the welding and soldering procedures. The electrical AC tests have been refined to detect short circuits as early as possible. The present scope of the tests allows a very strict quality control. Redundancy in the test facility is required to be able to bypass unexpected technical failures. The assumptions for the time-planning of the W7-X coil delivery have been too optimistic because technical failures and design changes were underestimated. The experience from this multinational collaboration, also in terms of interfaces and documentation, is extremely valuable for ITER and should be exploited by a thorough analysis of the difficulties encountered.

\section{Acknowledgements}

H. Ehmler acknowledges gratefully support from K. Hertel, A. Hölting, M. Gottschewsky (all from IPP) in collecting and preparing data. The author wants to thank H. Scheller (BNN) for critically reading the manuscript. 


\section{References}

[1] G. Grieger, Phys. Fluids B 4 (1992), 2081.

[2] C. Sborchia et al., IEEE Trans. Appl. Supercond. 16 (2006), 848..

[3] T. Rummel, K. Riße and H. Ehmler, Fus. Eng. \& Design, 75-79 (2005), 117-121.

[4] J. Baldzuhn et al., IEEE Trans. Appl. Supercond. 16 (2006), 763.

[5] J. Baldzuhn et al., Cryogenics 46 (2006), 507

[6] H. Scheller et al., IEEE Trans. Appl. Supercond. 16 (2006), 759.

[7] B. M. Petersen-Zarling, "Experience with High Voltage Tests of the W7-X Magnets in Paschen-Minimum Conditions", this conference.

[8] H. Ehmler et al., IEEE Trans. Appl. Supercond. 16 (2006), 767.

[9] R. Heller et al., Cryogenics 40 (2000), 561-567

[10] K. Riße et al., IEEE Trans. Appl. Supercond. 16 (2006), 890. 


\begin{tabular}{|c|c|c|c|}
\hline Test & $\begin{array}{l}\text { Total } \\
\text { Number }\end{array}$ & $\begin{array}{l}\text { Fraction } \\
\text { valid }\end{array}$ & Failure reasons \\
\hline Non-planar Coils & 10 tested & 6 accepted & High voltage insulation \\
\hline AC insulation CT $\left(3.2 \mathrm{kV}_{\mathrm{pp}}\right)$ & 12 & $92 \%$ & Shortcut in double layer \\
\hline DC insulation CT (10.4 kV) & 22 & $68 \%$ & $\begin{array}{l}\text { Coil insulation, insufficient } \\
\text { vacuum insulation of test facility }\end{array}$ \\
\hline Flow CT & 10 & $80 \%$ & - \\
\hline Leak CT $\left(<10^{-7} \mathrm{mbar}^{*} / \mathrm{s}\right)$ & 13 & $69 \%$ & $\begin{array}{l}\text { Leak in facility, too high } \mathrm{He} \\
\text { background }\end{array}$ \\
\hline Cool-down & 13 & $69 \%$ & Sensor failures \\
\hline $\begin{array}{l}\text { Strand copper residual } \\
\text { resistance ratio }(>160)\end{array}$ & 10 & $100 \%$ & 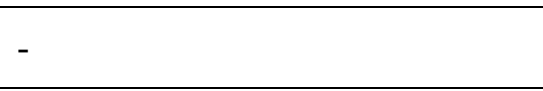 \\
\hline Warm-up & 12 & $75 \%$ & Sensor failures \\
\hline $\begin{array}{l}\text { Quench (by temperature } \\
\text { increase) }\end{array}$ & 7 & $86 \%$ & $\begin{array}{l}\text { Too high resistance on bus bar } \\
\text { connection }\end{array}$ \\
\hline Safety margin $(17.6 \mathrm{kA}, 5.7 \mathrm{~K})$ & 11 & $91 \%$ & $\begin{array}{l}\text { Too high resistance on bus bar } \\
\text { connection }\end{array}$ \\
\hline Joint resistance $(<6 n \Omega)$ & 11 & $91 \%$ & $\begin{array}{l}\text { Measurement technique (voltage } \\
\text { taps) }\end{array}$ \\
\hline $\begin{array}{l}\text { Paschen test after warm-up } \\
(9.1 \mathrm{kV} \text { DC) }\end{array}$ & 11 & $27 \%$ & Coil insulation \\
\hline Planar Coils & 6 tested & 3 accepted & $\begin{array}{l}\text { High voltage insulation, Al } \\
\text { welding, Cu-SS soldering }\end{array}$ \\
\hline AC insulation CT $\left(3.2 \mathrm{kV}_{\mathrm{pp}}\right)$ & 9 & $100 \%$ & - \\
\hline DC insulation CT (7.2 kV) & 12 & $75 \%$ & $\begin{array}{l}\text { Coil insulation, insufficient } \\
\text { vacuum insulation of test facility }\end{array}$ \\
\hline Flow CT & 5 & $100 \%$ & - \\
\hline Leak CT $\left(<10^{-7} \mathrm{mbar}^{*} \mathrm{l} / \mathrm{s}\right)$ & 8 & $38 \%$ & $\begin{array}{l}\text { Leaks in coils, leaks in facility, too } \\
\text { high He background }\end{array}$ \\
\hline Cool-down & 8 & $38 \%$ & Sensor failures \\
\hline $\begin{array}{l}\text { Strand copper residual } \\
\text { resistance ratio }(>160)\end{array}$ & 5 & $100 \%$ & 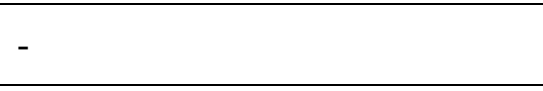 \\
\hline Warm-up & 7 & $29 \%$ & $\begin{array}{l}\text { Sensor failures, too high warm-up } \\
\text { speed }\end{array}$ \\
\hline $\begin{array}{l}\text { Quench (by temperature } \\
\text { increase) }\end{array}$ & 5 & $100 \%$ & Cr \\
\hline Safety margin $(16 \mathrm{kA}, 7.1 \mathrm{~K})$ & 5 & $100 \%$ & - \\
\hline Joint resistance $(<2.5 \mathrm{n} \Omega)$ & 5 & $20 \%$ & $\begin{array}{l}\text { Measurement technique (voltage } \\
\text { taps) }\end{array}$ \\
\hline $\begin{array}{l}\text { Paschen test after warm-up } \\
(6.3 \mathrm{kV} \mathrm{DC})\end{array}$ & 5 & $60 \%$ & Coil insulation \\
\hline
\end{tabular}

Table 1: Overview about the most important tests at cryogenic temperature (CT) and after warm-up (Paschen test). The total number of coils tested and accepted is shown in bold. All other data refer to the total number of individual tests and the fraction valid (some coils were tested more than once). The data cover more than three years of testing from $21^{\text {st }}$ June 2003 until $5^{\text {th }}$ September 2006. 


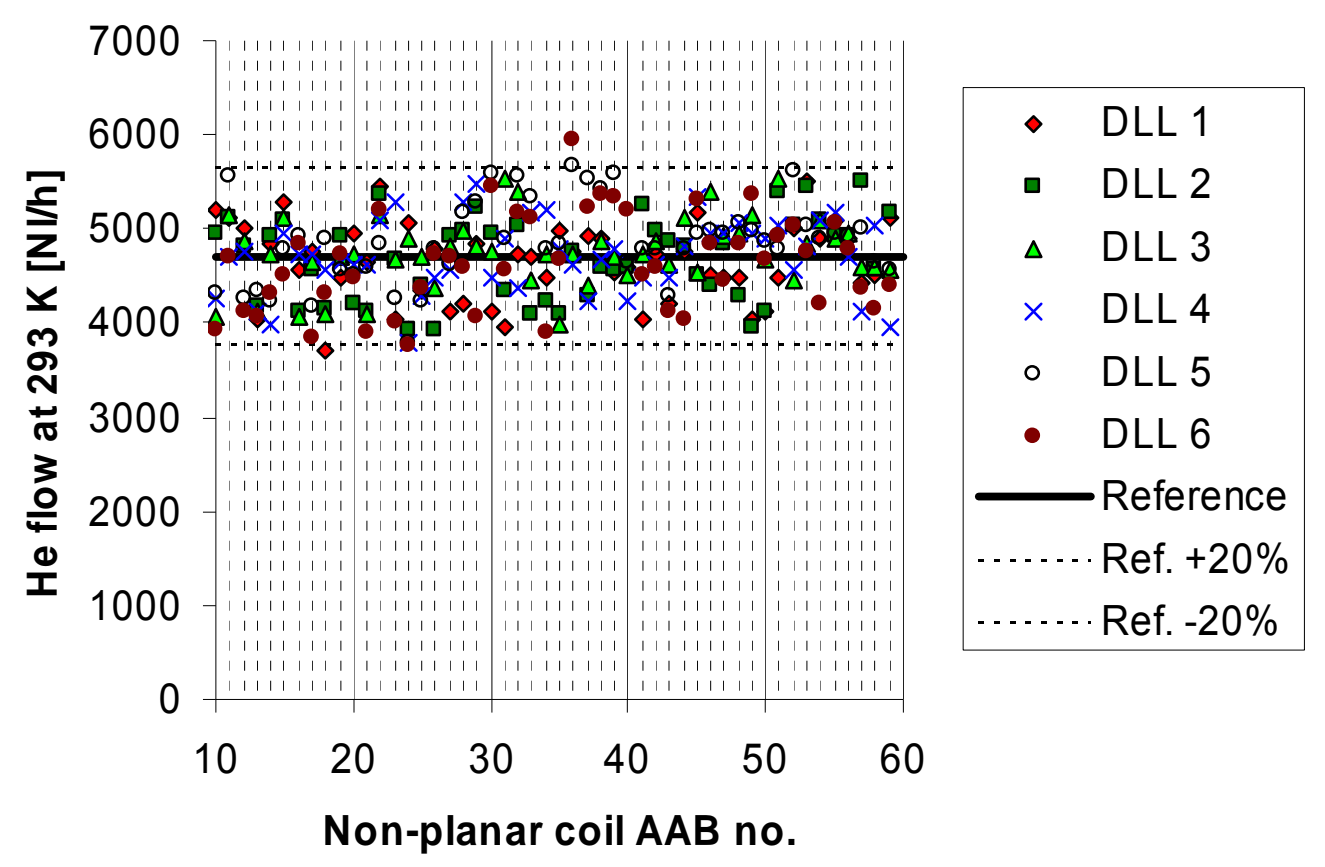

Figure 1: Helium flow rates of the non-planar winding packs. Each double layer length (DLL) has been measured individually.

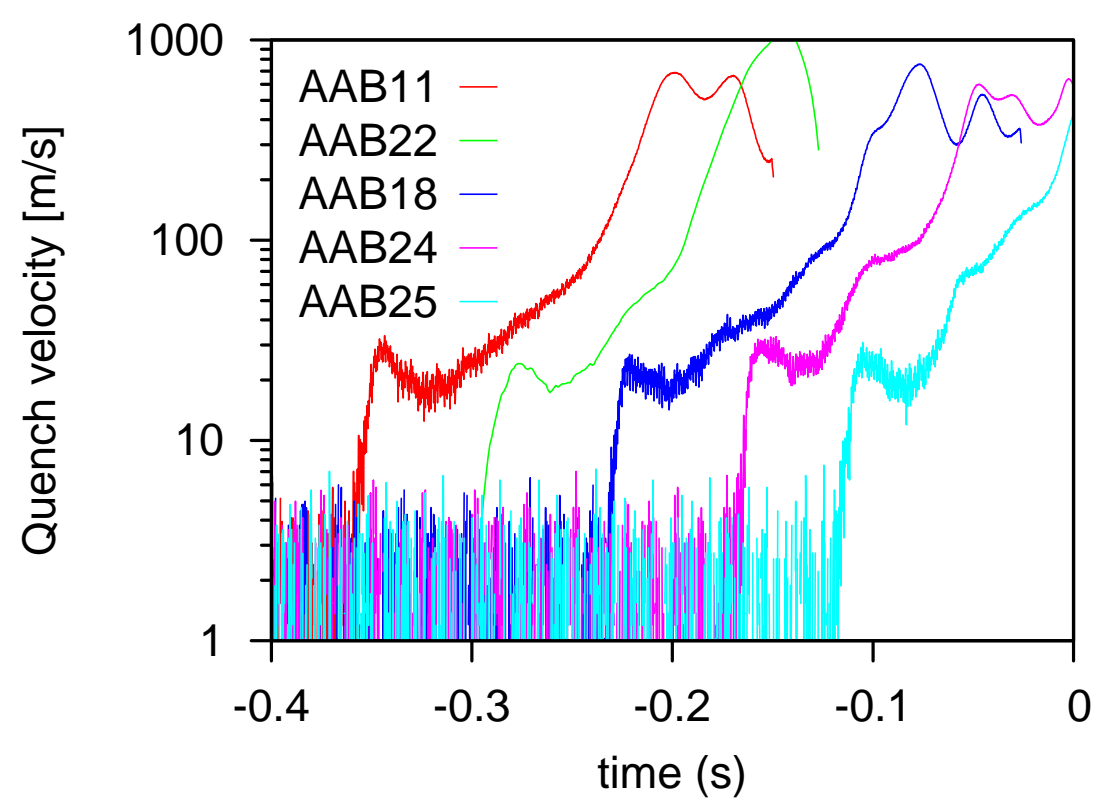

Figure 2: The speed of normal-conducting zone evolution (quench velocity), plotted for all five types of non-planar coils, shows a uniform behavior. 


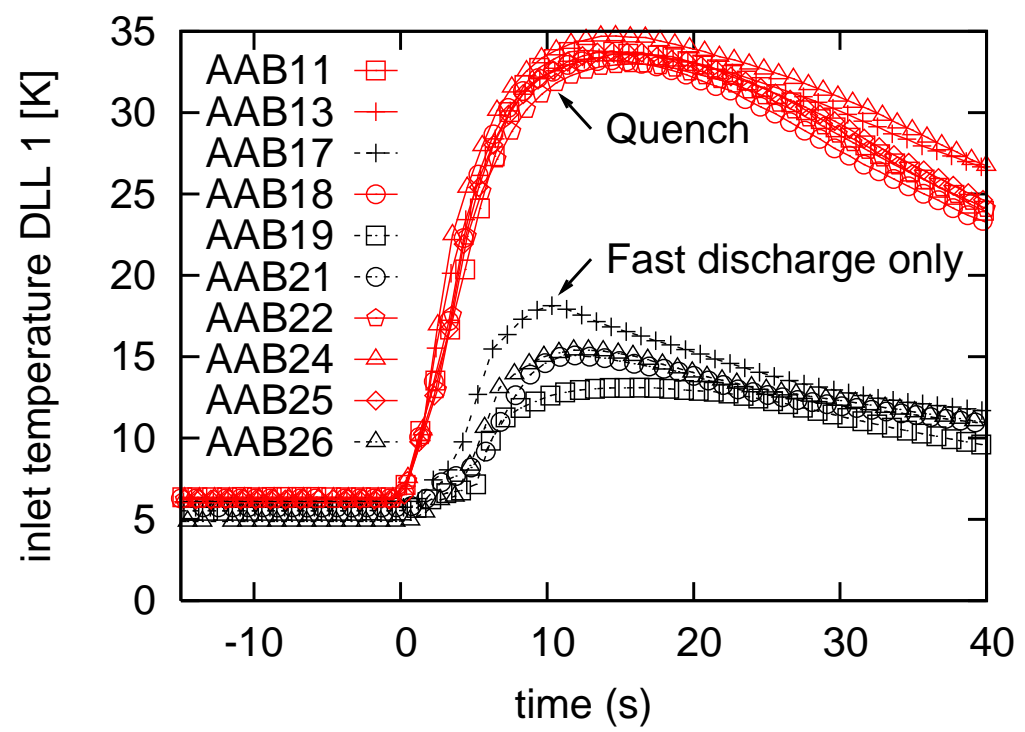

Figure 3: The temperature of the innermost layer after a fast discharge is plotted for all non-planar coils tested. If the coil is quenched before, the temperature rises to much higher values.

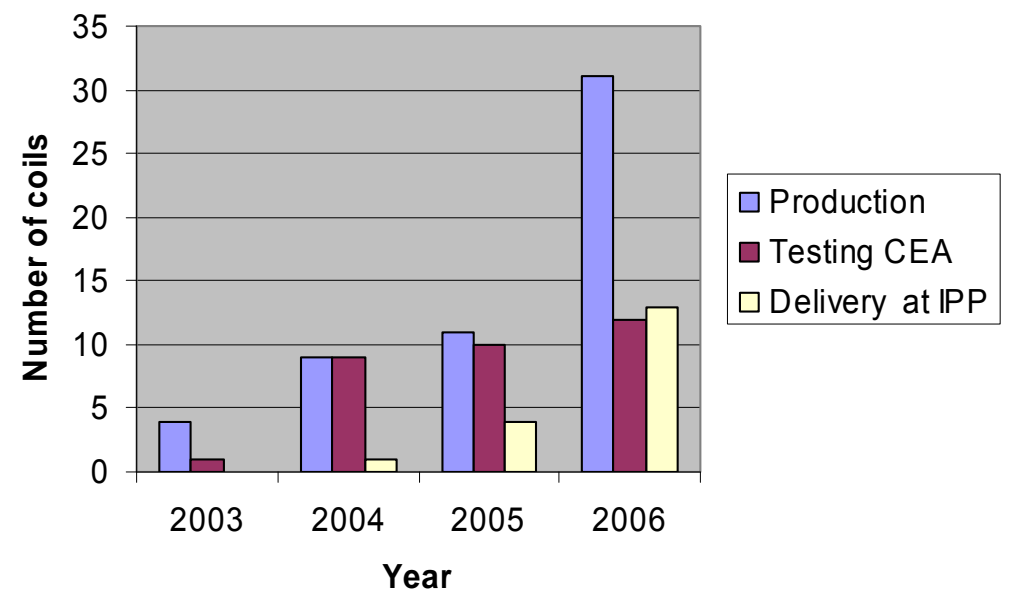

Figure 4: Production, tests and delivery of all W7-X coils (status from July 2006, total numbers for 2006 planned). 